\title{
Information System for the Governance of University Cooperation
}

\author{
Majida Laaziri \\ Information System Engineering Resarch Group \\ National School of Applied Sciences \\ Abdelmalek Essaadi University \\ Tetouan, Morocco \\ Khaoula Benmoussa \\ Information System Engineering Resarch Group \\ National School of Applied Sciences \\ Abdelmalek Essaadi University \\ Tetouan, Morocco
}

\author{
Samira Khoulji \\ Information System Engineering Resarch Group \\ National School of Applied Sciences \\ Abdelmalek Essaadi University \\ Tetouan, Morocco \\ Kerkeb Mohamed Larbi \\ Information System Engineering Resarch Group \\ Faculty of Sciences \\ Abdelmalek Essaadi University \\ Tetouan, Morocco
}

\begin{abstract}
Recognizing the impact of international cooperation in science and technology, all higher education institutions prioritize strategic partnerships. If setting up a partnership is important, its management, monitoring and evaluation of cooperation actions, regular communication among partners, and the ability to allow all parties to monitor the functioning of the partnership are more important. For good co-operation management, an information system becomes a mandatory condition. Abdelmaleek Essaadi's University team has set up an information system for the governance of a university cooperation called SIMACoop, to support cooperation between governments and universities, and to facilitate the process of partnership management. This system also helps in identifying the shared vision and goals of the partnership members and develops documents that define the partnership terms. In addition, SIMACoop has put in place procedures for maintaining and monitoring the partnership evolution [1]. The purpose of this article is to give a general presentation on SIMACoop's design and development for the governance of university cooperation.
\end{abstract}

Keywords-information system; the governance of university cooperation; SIMACoop platform; object-oriented methodology; $U M L$

\section{INTRODUCTION}

Moroccan universities and research institutions face the challenge of synchronization with the demands and expectations of modern society while reinforcing their actions on international level. A large academic and research university is not any more a sufficient condition to provide access to high quality education, if it does not cooperate with other major universities and organizations at national and international level. For this reason, all higher education institutions give importance to university cooperation, which enables the development of innovative international partnerships, student mobility, establishment of relationships and networks, experience and knowledge exchange, and generation of ideas and knowledge. In addition, university cooperation requires effective management to ensure the continuity of constructive and productive relations [2], and to allow all considered parties to monitor the functioning of the partnership. In this context and with the evolution of information systems in different fields, the Abdelmaleek Essaadi University (AEU) set up a tracking information system for the management of university cooperation called SIMACoop.

\section{SIMACOOP GENERALITIES}

SIMACoop is a monitoring system designed to support governments and universities in the cooperation, partnership and student exchange plans and programs, and to improve communication, collaboration and integration between universities and their partners, performance management, strategic planning, research performance evaluation and establishing of a sound policy for the development of the institutional relationship[3]. SIMACoop offers a range of services, it mainly gives the university and its partners the possibility to: do a follow-up of the activities of the cooperation projects, do a follow-up of cooperation agreements and their results, and get personalized follow-up of foreign students (Figure 1). It notifies the user of the dates of the cooperation project activities, whether they are imminent or behind schedule, and informs them of the dates of the agreements in force and the non-renewable agreements. Thus, this system can detect the strong points of cooperation in order to overcome its weaknesses, benefit from the exchange of experience, skills and competences, and raise the level of efficiency and productivity, monitor the implementation, the extent to which each party fulfills its obligations and commitments, and the respect of cooperation agreements with partner missions and their strategic objectives [1]. SIMACoop is a coherent information system centered in a global platform integrating several services that meet the administrative and academic needs (Figure 2). 


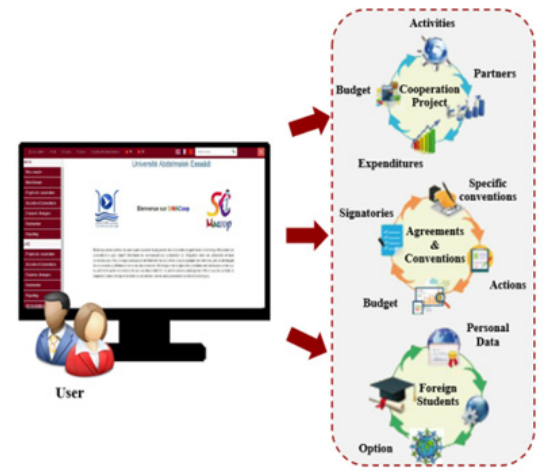

Fig. 1. SIMACoop features

\section{A. Administrative}

- Makes the partnership management process easier.

- Facilitates the work of the administration and allows it to accomplish its mission.

- Provides reliable, relevant and instant information

- Provides better partnership management.

- Follows the strategic objectives of the partnership.

- Detects successful actions and challenges.

- Allows regular communication among partners.

- Provides information about the evolution of the partnership.

- Ensures monitoring and evaluation of cooperation actions.

B. Academic

- Measures the evolutions and the consequences of the decisions taken.

- Helps the actors of the partnership in their activities.

- Schedules and controls the tasks of the partnership process.

- Allows effective communication.

- Adds depth and breadth to its impact on the scientific community.

- Identifies the shared vision and goals of the partnership members.

- Develops documents that define the partnership terms.

- Follows-up the partnership as it evolves.

- Allows all parties to follow the functioning of the partnership.

- Maintains constructive and productive relationships.

- Evaluates research.

- Shares and exchanges information.

- Reduces cost.

- Takes advantage of the exchange of experience, skills and competences.
- Raises the level of efficiency and productivity.

- Improves the quality of data reported by the institutions management.

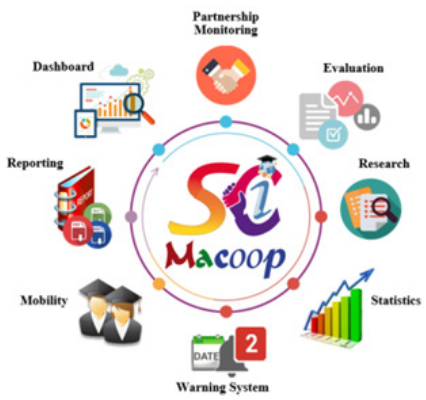

Fig. 2. Administrative and university services of SIMACoop

\section{OBJECT-ORIENTED METHODOLOGY}

Object-oriented technology is a new methodology that is widely applied in the field of software development. Objectoriented methodology (OOM) is a supreme technique for solving complex problems by ripping the problem into subtasks. OOM is a new approach to system development that encourages and facilitates the reuse of software components. By using OOM, higher productivity, lower maintenance costs and better quality can be achieved $[4,5]$. OOM requires objectoriented techniques to be used during system analysis, design, and implementation. This methodology allows to determine what the system objects are, how they behave over time or in response to events, and what responsibilities and relationships an object has to other objects. Object-oriented analysis allows seeing all the objects in a system, their commonalities, their differences and the way the system handles objects [6, 7]. During design, the overall architecture of the system is described. During the implementation phase, the class objects and interrelations of these classes are translated and effectively coded. There are several object-oriented development methods (OOMs). In the design of our information system, we used the object modeling technique (OMT) because it is the most developed one, and covers a good part of the system development cycle. OMT is an object-oriented software development methodology given by James Rumbaugh. This methodology describes a method of analysis, design and implementation of a system using an object-oriented technique. It is a fast and intuitive approach to identify and model all the objects that constitute a system [8]. OMT consists of three basic models, each capturing important aspects of the system, namely the object model which describes the static, structural and system data, the dynamic model that describes the temporal, behavioral and control aspects of the system and the functional model that describes the transformational and functional aspects of the system [9, 10]. OMT methodology supports the entire life cycle of the system, according to five main phases [11-13].

\section{A. System Analysis}

As in any other system development model, system analysis comes first. In this phase, the developer interacts with the system user to know the user's needs and analyzes the system 
to understand how it works. On the basis of this study, the analyst prepares a model of the desired system. This model is purely based on what the system needs to do. At this stage, the implementation details are not taken into account. Only the model of the system is prepared on the basis of the idea that the system consists of a set of interacting objects. The important elements of the system are underlined.

\section{B. System Design}

System design is the next stage of development, where the overall architecture of the desired system is decided. The system is organized as a set of subsystems interacting with each other. When designing the system as a set of interacting subsystems, the analyst considers the specifications observed in the system analysis as well as the user-imposed requirements. The analysis of the system consists in perceiving the system as a set of interacting objects. A larger system can also be seen as a set of smaller interacting subsystems that are themselves composed of a set of interacting objects. When designing the system, the focus is on the objects that constitute the system, not on the processes that are running in the system.

\section{Object Design}

In this phase, the details of system analysis and system design are implemented. The objects identified in the design phase of the system are designed. In this phase, the implementation of these objects is decided in the form of required data structures and interrelationships between objects. This concept is known as class creation. In this phase of the development process, the designer decides classes in the system based on these concepts. It decides whether classes should be created from scratch, whether existing classes can be used as is, or new classes can be inherited.

\section{Implementation}

During this phase, the class objects and interrelations of these classes are translated and effectively encoded using an object-oriented programming language. The required databases are created and the entire system is transformed into an operational system.

\section{E. Testing}

This phase aims to test the system in implementation. Three cases are produced and used:

- Test cases: what to test in the system.

- Test procedures: the procedures that allow running the test.

- Test components: the environment needed to actually perform the test cases.

\section{OOAD WITH AN UML, OMG STANDARD.}

Object Oriented Analysis and Design (OOAD) is a technical approach used in the analysis and design of the system through the application of paradigm and object-oriented concepts, including visual modeling, applied throughout the cycle system development [8]. It models a system as a group of objects. One of the most used notations to represent the objects of a system and how they interact with each other is the unified modeling language (UML). Object management group (OMG) for object-oriented modeling, standardized UML in 1997. It is a graphical language for data modeling and processing (objectoriented), that allows the specification, representation and construction of computer system components, it combines widely accepted concepts from a number of object-oriented modeling techniques and is inherited from several other methods like OMT [14]. It is intended to model information systems and covers the different phases of an object development (analysis, design and implementation) $[15,16]$. It improves and facilitates communication, representation and understanding of object solutions [4].

\section{SYSTEM ARCHITECTURE DESIGN}

The design of the system architecture is how system functionality is to be provided by the system components, where the system represents a set of components that perform the defined functions [17]. The design process of the information system architecture focuses on the decomposition of the system into different components and their interactions to satisfy functional and non-functional requirements. Figure 3 provides an overview of the design and development of the SIMACoop information system.

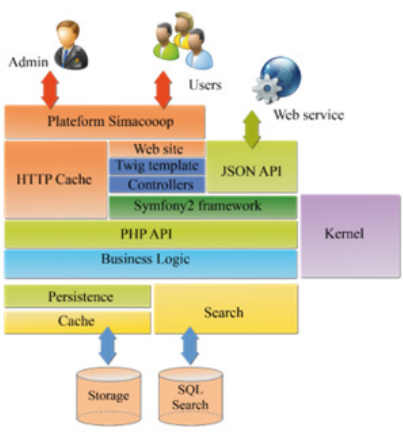

Fig. 3. SIMACoop architecture

According to Figure 3, the realization of the SIMACoop information system was based on the functionality of the symfony framework and the architecture of the MVC paradigm. Thanks to Symfony's functionalities, our system has benefited from a well-structured modular workspace with a clear and maintainable code, the code is separated in three layers according to the MVC model, it is characterized by an object-relational mapping layer (ORM) and a data abstraction layer, ensuring data separation, display, processing, and actions [18].

\section{RESULT}

In the SIMACoop information system, there are three types of actors who can access the platform: project manager, dean, university president. Their functions are different, so each actor corresponds to a space in the platform as follows:

\section{A. Project Manager's Space}

SIMACoop offers the project manager an account to enter the general information of his cooperation project, the information of the project partners, the activities, the expenses and the budget (Figure 4 [3]). 


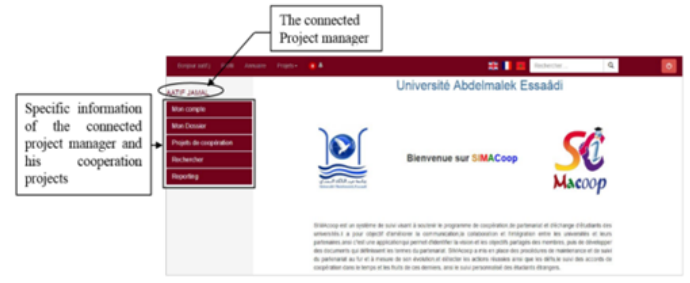

Fig. 4. Project manager's space

SIMACoop allows the project manager to:

- Follow the activities of cooperation projects.

- Manage projects better.

- Communicate with other partners (government, universities, national and international institutions, ...).

- Be notified of project activities that are imminent or delayed.

- Exchange and share information and cooperation documents with other project managers.

B. Dean's Space

SIMACoop offers the dean of the institution an account that enables him to introduce his information as project manager and to add the project managers belonging to his institution in the SIMACoop platform, the validation of their partnership activities, and all the partners of his establishment (Figure 5 [3]).

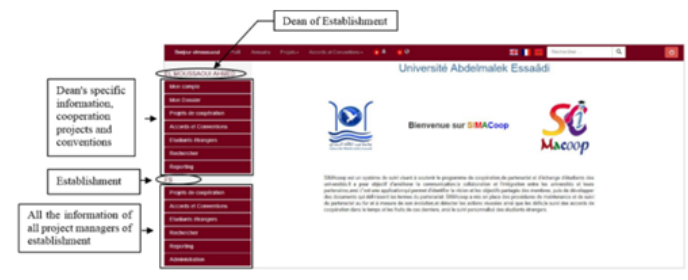

Fig. 5. Dean's space

SIMACoop allows the dean to:

- Manage the budget and the expenses of the cooperation projects and the partnership agreements.

- Follow the agreements and conventions of the institution over time.

- Make a personalized follow-up of the foreign students of the establishment.

- Download the annual report of the activities of the cooperation projects and partnership agreements of the institution.

- Exchange information and share cooperation documents.

- Provide visibility to all project managers at the institution, and all national and international partners.
- Be advised of the dates of activities carried out, unrealized projects and the agreement dates that are in force or renewed.

- Follow the evolution and the execution of the actions of the partnerships of the establishment.

- Detect successful partnership actions and challenges.

- Ensure the continuation of constructive and productive relationships.

\section{University Administrator's Space}

SIMACoop offers the president of the university an account for two roles: he can introduce his information as project manager and he is also the manager of the platform. He has total visibility on the database, his task is to manage the entire system, and he is in charge of creating and validating the accounts of all the project managers who belong to the institutions from his university in the SIMACoop platform. Therefore, he specifies the access rights of each user (Figure 6 [3]).

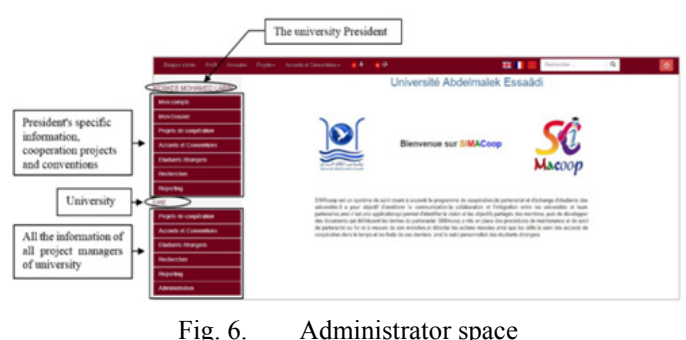

SIMACoop allows the president to:

- Validate the accounts of the project managers of the university.

- Ensure the smooth running of all agreements and partnership agreements of the university.

- Order the budgets and expenses of cooperation projects and the university.

- Check and accredit all the information concerning all cooperation partnerships of the university.

- Download the annual report of the projects and cooperation partnerships of the university.

\section{CONCLUSION}

The use of information systems in the university has become a reality, and a central part of its operation, because they provide universities with management tools that meet their needs, and help all users in their activities. They schedule and control tasks and they enable effective communication. As the problems faced by university communities become more complex, the idea of a management information system on university cooperation can be very promising. Through partnerships, the university can contribute and benefit from the efforts of other higher education institutions. Through a cooperative information system, universities can accelerate 
learning and disseminate skills and knowledge. In addition, they can add depth and breadth to their impact on the scientific community.

\section{REFERENCES}

[1] M. Laaziri, K. Benmoussa, S. Khoulji, K. Mohamed Larbi, "SIMACoop: a Framework Application for the Governance of University Cooperation", Transactions on Machine Learning and Artificial Intelligence, Vol. 5, No. 4, pp. 785-794, 2017

[2] R. de Vry, G. Watson, "University of Delaware's Faculty-IT Partnership: Educational Transformation through Teamwork", The Technology Source, Available at: http://technologysource.org/article/ university_of_delawares_facultyit_partnership/

[3] SIMACoop, available at: http://simacoop.uae.ac.ma/

[4] U. A. Khan, I. A. Al-Bidewi, K. Gupta, "Object-Oriented Software Methodologies: Roadmap to the Future", International Journal of Computer Science Issues, Vol. 8, No. 5, pp. 392-396, 2011

[5] M. R. B. Prakash, H. S. Chandrasekharaiah, "An object oriented perspective for AC/MTDC system simulation", IEEE International Conference on Intelligent System Application to Power Systems, Orlando, USA, January 28-February 2, 1996

[6] H. Lee, C. Lee, C. Yoo, "A scenario-based object-oriented methodology for developing hypermedia information systems", IEEE 31st Hawaii International Conference on System Sciences, Kohala Coast, HI, USA, January 9, 1998

[7] R. Chalmeta, T. J. Williams, F. Lario, L. Ros, "Developing an ObjectOriented Reference Model for Manufacturing", IFAC Proceedings Volumes, Vol. 30, No. 1, pp. 351-356, 1997

[8] S. Hong, G. van Den Goor, S. Brinkkemper, "A formal approach to the comparison of object-oriented analysis and design methodologies", IEEE 26th Hawaii International Conference on System Sciences, Wailea, HI, USA, January 8, 1993

[9] J. Osis, O. Ivasiuta, P. Rusakovs, "Advanced Object-Oriented Modeling Techniques for Large Scale Systems”, IFAC Proceedings Volumes, Vol. 31, No. 20, pp. 787-792, 1998

[10] R. H. Bourdeau, B. H. C. Cheng, “A Formal Semantics for Object Model Diagrams", IEEE Transactions on Software Engineering, Vol. 21, No. 10, pp. 799-821, 1995

[11] UKEssays, Two Object Oriented Methodologies Booch And Rambaugh Information Technology Essay, available at: https://www.ukessays.com/ essays/information-technology/two-object-oriented-methodologiesbooch-and-rambaugh-information-technology-essay.php

[12] M. P. Selvan, K. S. Swarup, “Object methodology - techtorial”, IEEE Power Energy Magazine, Vol. 3, No. 1, pp. 18-29, 2005

[13] Visual Basic Tutorials, Object Oriented Methodology Life Cycle Model, available at: http://www.freetutes.com/systemanalysis/sa2-objectoriented-methodology.html

[14] G. Booch, J. Rumbaugh, I. Jacobson, The Unified Modeling Language User Guide, Addison Wesley, 1998

[15] S. Servigne, "Conception, architecture et urbanisation des systemes d'information", in: Encyclopædia Universalis, Encyclopædia Britannica, 2008 (in French)

[16] O. Glassey, J. L. Chappelet, Comparaison de trois techniques de modélisation de processus: ADONIS, OSSAD et UML, Institute de Hautes Etudes en Administration Publique, 2002 (in French)

[17] Tutorials Point, OOAD - Object Oriented System, available at: https://www.tutorialspoint.com/object_oriented_analysis_design/ooad_o bject_oriented_system.htm

[18] Symfony 4.0 Documentation, available at: https://symfony.com/ doc/current/index.html 